\title{
A quem pertence 0 estudo da democracia? Sociologia, ciência política e a promessa da interdisciplinaridade na Sociologia política desde 1945
}

\section{Resumo}

Interdisciplinaridade é a integração entre duas ou mais disciplinas que produz conhecimento emergente, original, interessante e útil. A interdisciplinaridade é mais promissora quando a relação entre as disciplinas integradas é forte e simétrica. A sociologia política já foi considerada uma ponte natural entre as disciplinas de sociologia e ciência política. Contudo, em diversas medidas bibliométricas da base de citações da Web of Science entre 1945 e 2013, observa-se que os vínculos entre sociologia e ciência política são cada vez mais fracos exatamente nas áreas centrais da sociologia política: democracia, participação política, sociedade civil e movimentos políticos. A partir da década de 1970, a ciência política apropriou-se do estudo da democracia e também de alguns dos temas centrais da sociologia política. A sociologia política se tornou um exemplo de como uma grande promessa de interdisciplinaridade pode malograr. Neste artigo, o demonstramos empiricamente e abordamos as razões desse malogro ${ }^{1}$.

Palavras-chave: Sociologia Política. Interdisciplinaridade. Democracia. Popularidade e propriedade na ciência.

\footnotetext{
"Instituto de Filosofia e Sociologia da Academia Polonesa de Ciências (Polônia).

"Universidade do Estado de Ohio (EUA) e Instituto de Filosofia e Sociologia da Academia Polonesa de Ciências (Polônia).

${ }^{1}$ Agradecemos a Kazimierz M. Slomczyński, Peter Tunkis e Irina Tomescu-Dubrow por seus valiosos comentários.
} 
Who Owns the Study of Democracy? Sociology, Political Science and the Interdisciplinary Promise of Political Sociology since $1945^{\star}$

\section{Abstract}

Interdisciplinarity is the integration of two or more disciplines that produces emergent, original, interesting and useful knowledge; it is most promising when the relationship of the integrated disciplines is strong and symmetrical. Political sociology was once considered to be a natural bridge between the disciplines of sociology and political science. Yet, in various bibliometric measures from the Web of Science citation database from 1945 to 2013, we find that the relationships between sociology and political science grew weak and asymmetrical exactly in the core areas of political sociology: democracy, political participation, civil society and social movements. As of 1970, political science began to own the study of democracy, and some of the core areas of political sociology besides. Political sociology has become a case study in how great promise for interdisciplinarity falls short. In this article, we demonstrate this empirically, and address why.

Keywords: Political sociology. Interdisciplinarity. Democracy. Disciplinary popularity and ownership.

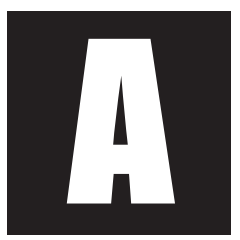

sociologia política, uma possível ponte entre a sociologia e a ciência política, por muito tempo portou uma grande promessa interdisciplinar (Sartori, 1969). O potencial para a interdisciplinaridade - a integração de duas ou mais disciplinas que produz conhecimento emergente, original, interessante e útil - é mais promissor quando a relação entre as disciplinas integradas é forte e simétrica (Wagner et al., 2011; National Academies, 2004; Dubrow, 2011). A força e a simetria das relações entre as disciplinas dependem da relativa semelhança de seus objetos de estu-

•Tradução: Liana Fernandes (UFRGS). 
do, dos métodos de investigação, da dimensão da profissão e seu aparato disciplinar e trajetória história (Dubrow, 2011). No campo da sociologia política, a sociologia e a ciência política parecem ser semelhantes exatamente nessas áreas.

No entanto, percebe-se que as relações entre a sociologia e a ciência política são fracas e assimétricas exatamente em áreas fundamentais da sociologia política: democracia, participação política, sociedade civil e movimentos sociais. Na maioria dos casos, esses conceitos fundamentais encontram-se nos periódicos da ciência política, e as principais publicações das duas disciplinas não citam os trabalhos uma da outra com uma frequência que indique interdisciplinaridade.

Este artigo aborda um enigma relevante para o estudo da interdisciplinaridade e para a compreensão do passado, presente e futuro da sociologia política: mesmo quando muitos dos pré-requisitos para interdisciplinaridade são atendidos, esse tipo de conhecimento pode não corresponder às expectativas (Dubrow, 2011; Jacobs; Frickel, 2009; Jacobs, 2014). As disciplinas ocupam um lugar central na academia, uma posição privilegiada que a recente onda de interdisciplinaridade nas universidades e institutos de pesquisa ainda precisa desbancar (Jacobs, 2014). Este artigo adota uma perspectiva socioconstrutivista das disciplinas, no sentido de que se define uma disciplina pelo que ela publica em seus principais periódicos (ver também Gove, 1979, p. 799). Apesar do status da sociologia política, na década de 1960, como um potencial campo de pesquisa interdisciplinar (Sartori, 1969, p. 200), a subsequente separação entre a sociologia e a ciência política (Sigelman, 2010, p. 884-885) criou um ambiente em que a sociologia política nunca chegou a ser interdisciplinar. A sociologia política tornou-se um caso exemplar de como um grande potencial de interdisciplinaridade pode frustrar as expectativas. Neste artigo, isso será empiricamente evidenciado e abordaremos os motivos. 
Sociologias, Porto Alegre, ano 17, no 38, jan/abr 2015, p. 92-120

\section{Breve histórico da sociologia e da ciência política ${ }^{4}$}

A sociologia e a ciência política compartilham uma história, uma perspectiva geral e tendências metodológicas similares e, como outras disciplinas, sua relação disciplinar é dinâmica e influenciada por eventos mundiais. Ambas surgiram no final do século XIX e, na época, eram fortemente ligadas a ramos disciplinares aos "terceiros" disciplinares da economia e da história (Gunnel, 2006; Young, 2009). Somente no início do século XX a sociologia e a ciência política começaram a se distanciar desses vínculos e construir seu próprio aparato disciplinar: departamentos acadêmicos, associações profissionais e periódicos (Young, 2009; Farr, 2003). Como aponta Young (2009, p. 99-102), a sociologia, a economia e a ciência política já tiveram um relacionamento forte; até a Segunda Guerra Mundial, reuniões, e até mesmo discursos presidenciais conjuntos eram a regra.

O período pós-segunda guerra, até a década de 1970, caracterizou-se pela "ascendência" das ciências sociais, em muito devida à ampliação e democratização do ensino superior na Europa e nos Estados Unidos (Ross, 2003, p. 229) e à ascendência geral da ciência ocidental como um meio intelectualmente satisfatório de produzir explicações formais para o caos que parecia reinar em toda parte (ver também Sartori, 1969, p. 196). A ciência era tão importante para certas figuras centrais da pesquisa política no início do século XX que, ao criarem sua associação profissional, escolheram o termo como parte de seu nome (Farr, 2003, p. 306-307; ver também Gunnell, 2006, p. 481-483). Contudo, como aponta Sigelman (2010), foi somente nas décadas de 1950 e 1960 que os cientistas políticos buscaram inserir a disciplina em uma base mais 'científica'(p. 884).

\footnotetext{
${ }^{4}$ Este relato é focado nas histórias da sociologia e da ciência política nos países da Europa e América do Norte. A América Latina tem sua trajetória histórica particular. Focamo-nos nas sociedades ocidentais do norte porque elas foram mundialmente as propulsoras intelectuais da sociologia e da ciência política desde o surgimento das duas disciplinas.
} 
Sociologias, Porto Alegre, ano 17, no 38, jan/abr 2015, p. 92-120

A partir de 1945 até o final dos anos 1960, a ciência política focou-se no behaviorismo, com ênfase crescente na ciência, na quantificação, em sistemas e no comportamento político (Farr, 2003; Dryzek, 2006, p. 490).

A década de 1970 tornou-se um ponto de virada na história da relação entre a sociologia e a ciência política: elas se distanciaram. Nos anos 1970, sociólogos e cientistas políticos ocidentais reavaliaram seus pressupostos e focos disciplinares (Ross, 2003, p. 234-237; Sigelman, 2010, p. 883-885). Ross (2003, p. 234) argumenta que o esquerdismo das ciências sociais conferiu relevância nas ciências sociais a fenômenos que antes eram pouco pesquisados, tais como gênero, raça e orientação sexual. Nessa época, alguns sociólogos colocaram em questão se a sociologia seria uma "ciência" (Gove, 1979, p. 799). Isso pode estar relacionado com a ascensão do pós-modernismo como um paradigma de pesquisa, embora não tenha freado os avanços importantes e a crescente popularidade dos métodos quantitativos em sociologia ou ciência política nos principais periódicos (Porter, 2003). A sociologia e a ciência política passaram a distanciar-se ainda mais à medida que disputas internas se estabeleciam em cada uma dessas disciplinas. Disputas através das quais elas se comparavam a outras ciências sociais e às ciências naturais ${ }^{5}$. Desde os anos 1970, a ciência política sustentou muitas das tradições metodológicas da era behaviorista, com uma forte ênfase no Estado como sendo em boa medida autônomo em relação às forças sociais. Como argumenta Dryzek (2006, p. 491), [o]pondo-se ao suposto reducionismo societal da era behaviorista, os novos estatistas viam o Estado como uma variável independente, no sentido de que os agentes públicos poderiam agir com interesses próprios que não refletissem simplesmente as forças sociais. A

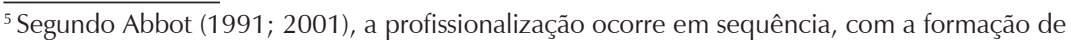
departamentos e outros aparatos disciplinares, completando-se com uma mudança do conhecimento produzido. Disputas entre disciplinas moldam os focos disciplinares dos contendores. 
Sociologias, Porto Alegre, ano 17, no 38, jan/abr 2015, p. 92-120

ciência política intensificou seu foco na política, enquanto a sociologia continuou a tratá-la como um dos muitos fatores inter-relacionados que influenciam pensamentos e comportamentos humanos.

\section{A promessa interdisciplinar da sociologia política}

Dado que tanto a sociologia quanto a ciência política compartilham uma devoção aos métodos de investigação científica, por muito tempo se supôs que a sociologia política fosse a principal ponte entre essas disciplinas. O estudo da sociologia política tem um século de história (Hicks et al., 2005, p. 1; Sartori, 1969; para um panorama histórico mais recente, consulte Mitra; Pehl, 2010). A sociologia política e a ciência política têm sido apontadas como "profundamente interdependentes" em sua relação e muito similares em "metateoria e método" (Hicks, 1995, p. 1219) (Sartori, 1969, p. 198 tem um argumento semelhante). Hicks (1995) chega a escrever que "os sociólogos políticos vivem dos reprocessamentos, feitos por cientistas políticos, de materiais sociológicos politicamente brutos (p. 1220) ${ }^{6}$.

As relações disciplinares dependem muito de um objeto de estudo comum; para a sociologia política, a definição do mesmo - política e sociedade - é visivelmente vaga. Segundo o departamento de Sociologia Política da American Sociological Association (ASA), o estudo da sociologia política engloba a "compreensão sociológica de fenômenos políticos" Comitê de Sociologia Política (CPS), um grupo multidisciplinar que une os departamentos de sociologia política da International Sociological Association (ISA) e da International Political Science Association (IPSA), não oferece uma definição mais sólida. De acordo com seus estatutos, esse é um grupo

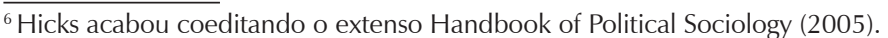

${ }^{7}$ http://asapoliticalsoc.org/section-information/, acesso em 17 de junho de 2014.
} 
dedicado ao diálogo interdisciplinar entre estudiosos e ideias" a respeito da "relação entre fenômenos políticos e sociológicos ${ }^{8}$. O volumoso Handbook of Political Sociology: States, Civil Societies and Globalization, editado por Thomas Janoski e colaboradores e publicado em 2005, dispõe de 32 capítulos e mais de 800 páginas em sua tentativa de fornecer uma visão integrada das principais teorias e descobertas na sociologia política (Hicks et al. 2005, p. 4). Talvez sabiamente, a própria sociologia política não é especificamente definida para além das vagas "bases sociais da política" (p. 4).

A "sociologia política" já foi considerada diferenciada de outros estudos sobre sociedade e política, como um esforço conscientemente interdisciplinar. Sartori (1969) argumentou que, para se entender o que é a sociologia política, deve-se primeiro distingui-la da sociologia da Política. Essa última é uma mera "redução sociológica" (p. 200) que "inequivocamente indica um subcampo" da sociologia (p. 195) e nada tem de inerentemente interdisciplinar. A sociologia política é, supostamente, diferente."A sociologia política", afirmou Sartori (1969, p. 200): é um híbrido interdisciplinar que tenta combinar variáveis explicativas sociais e políticas [ênfase no original].

Ciência política e sociologia compartilham alguns conceitos, mas a adoção mútua dos mesmos é rara e lenta (Sigelman, 2010). Como destaca Sigelman (2010, p. 884) em sua análise abrangente das relações conceituais entre a sociologia e a ciência política, apesar dos laços históricos [da sociologia política] com a ciência política, as duas não são, de forma alguma, contíguas. Para os sociólogos, a sociologia política é uma oportunidade de explicar a política com os fenômenos sociais, ou de explicar os fenômenos sociais com a política. Para os cientistas políticos, a política não pode ser evitada, mas os fenômenos sociais não-políticos podem (Dryzek 2006, p. 491).

${ }^{8}<$ http://www.isa-sociology.org/rcs/rc18_st.htm>, acesso em 17 de junho de 2014. Deve-se observar que a rede de pesquisa em Sociologia Política da ESA diz: "O site da rede de pesquisa em Sociologia Política da ESA é um portal para o debate das transformações no poder e ordem política na Europa e fora dela". <http://www.europeanpoliticalsociology.eu/>, acesso em 22 de junho de 2014. 
A popularidade e a importância da sociologia política para a sociologia e para a ciência política têm sido debatidas. A sociologia política já foi uma área vibrante da ciência política que inspirou uma série de análises sobre seu presente e especulações sobre seu futuro (Bendix; Lipset, 1957; Lipset, 1965; Sartori, 1969). Há quem veja um declínio de sua importância política para as duas disciplinas. De acordo com um livro recente sobre o "estado da arte" em ciência política, a Sociologia Política, anteriormente uma importante ou emblemática subdisciplina na evolução da ciência política, já não desempenha mais esse papel disciplinar central (Stein; Trent 2010, p. 7) ${ }^{9}$. Nessa obra, van Deth (2010, p. 106) argumenta que a sociologia política já não é tratada como uma subdisciplina muito importante na sociologia ou na ciência política ${ }^{10}$. O dissenso pode assumir grandes proporções. Hicks et al. (2005) argumentam que não só a sociologia política é uma das principais áreas da sociologia como também tem sido "estimulada" por diversos processos e transformações teóricas (p. 1)11. Em contraponto, sobre o campo de forma geral, van Deth (2010, p. 105) escreve: os tempos áureos da sociologia política já passaram.

Até 1969, sugeria Sartori, a sociologia política não havia atingido seu potencial interdisciplinar: o estabelecimento da sociologia política como

\footnotetext{
${ }^{9}$ Mitra e Pehl (2010: 14) argumentam que a centralidade da sociologia política nas ciências sociais varia de país para país.

${ }^{10}$ Embora a maioria dos exemplos de van Deth seja da ciência política.

${ }^{11}$ Utilizando dados do final da década de 1990, Hicks et al. argumentam que a sociologia política é popular (2005): "em 1999, entre 17\% e 20\% dos artigos no American Journal of Sociology e no American Sociological Review, e cerca de 20\% dos livros resenhados pela Contemporary Sociology [...] tratavam de sociologia política" (1). Eles não descrevem como chegaram a esses números. Confirmamos a continuada e relativa popularidade. Utilizando medidas bibliométricas da base de dados da Web of Science, tendo "political sociology" como tema, determinou-se que, entre 1945 e 2013, cerca de 850 produções acadêmicas no tema "political sociology" foram desenvolvidas, incluindo cerca de 370 artigos, muitos dos quais foram publicados nos principais periódicos de sociologia, como o American Sociological Review, Social Forces e o British Journal of Sociology, muitos dos quais publicados no século XXI.
} 
uma abordagem efetivamente interdisciplinar, como uma interfertilização equilibrada entre sociólogos e cientistas políticos, é mais uma tarefa para o futuro do que uma conquista atual (p. 200). Em meados dos anos 2000, apesar da aspiração de Sartori por um híbrido, o nome "sociologia política" não mais implica imediatamente a interdisciplinaridade. No livro Handbook of Political Sociology, os autores parecem indicar uma preocupação com o lado sociológico da sociologia política ao afirmar (em nota de rodapé), [o] presente manual reflete nossas percepções do que falta à própria sociologia, no qual também nos valemos da ciência política e áreas afins e usamos livremente de suas realizações (p. 5). Em outro panorama da sociologia política, van Deth (2010, p. 105) escreveu que os principais conceitos estudados no campo, juntamente com suas teorias e métodos, foram apropriados por outros campos e subdisciplinas. A interdisciplinaridade presente da sociologia política pode jamais ter acontecido, e seu futuro interdisciplinar nunca chegou.

\section{Principais conceitos em sociologia política}

A democracia e os conceitos que envolvem sua essência - participação política, sociedade civil e movimentos sociais - permanecem sendo centrais para a relação entre sociedade e Estado, e, portanto, para a própria sociologia política. Escolhemos a democracia como foco, porque, mais do que qualquer outro fenômeno, ela passou a definir a política pós-Segunda Guerra. Como tal, tornou-se um tema de estudo popular entre acadêmicos, junto com os conceitos de participação política, sociedade civil e movimentos sociais que captam elementos essenciais da governança democrática. A participação política inclui subtemas populares, como o voto, os protestos e outras formas de mobilização democrática. A sociedade civil desenvolveuse como a interface entre o povo e o governo. Os movimentos sociais são 
Sociologias, Porto Alegre, ano 17, no 38, jan/abr 2015, p. 92-120

uma forma coletiva de participação política, sendo uma força mais focada na mudança social do que em momentos isolados de participação política e o seu lócus, a sociedade civil. Suspeitamos que os movimentos sociais se inclinarão para a sociologia, uma vez que, na década de 1970, o próprio campo passou de um foco em ideologias políticas para tópicos mais sociológicos relativos a mobilização. E, embora a "oportunidade política" seja um fator chave, a atenção às questões associadas como características organizacionais e motivações pessoais tornou-se mais comum do que a ideologia do movimento (Walder, 2009).

\section{Popularidade e propriedade}

Apesar da incerteza relacionada a ela, a sociologia política ainda é a principal ponte entre a sociologia e a ciência política. Nela, as duas disciplinas compartilham um objeto de estudo, resumidamente descrito como o estudo da relação entre o Estado e a sociedade (Mitra; Pehl, 2010). Contudo, argumentos anteriores e algumas pesquisas empíricas sugerem que essa relação é frágil e assimétrica. Quanto à fragilidade da relação, Sigelaman (2010) demonstra empiricamente que poucos conceitos importantes são compartilhados entre a ciência política e a sociologia, e que os poucos que o são podem levar décadas até serem adotados nos principais periódicos de cada uma das áreas. Quanto à simetria, Hicks (1995, p. 1220) e Sigelman (2010, p. 885), entre outros, afirmam que a ciência política empresta mais conceitos da sociologia do que o oposto. Contudo, isso ainda não foi investigado com relação aos principais conceitos da sociologia política.

Neste artigo, empregamos os conceitos de popularidade e propriedade (ownership) de uma disciplina. A popularidade refere-se à produção acadêmica total em qualquer tema de pesquisa da disciplina. A popularidade, como a fama, é relativa tanto a outros conceitos no campo quanto a 
outras disciplinas. Espera-se que a democracia seja popular, especialmente em relação aos seus conceitos satélite, e também que essa popularidade tenha diferentes graus entre as disciplinas, sendo maior nos canais da ciência política do que em qualquer outra.

Em determinado momento, a popularidade relativa da disciplina se transforma em "propriedade" da disciplina. Não nos referimos aqui ao sentido de propriedade intelectual ${ }^{12}$; mais exatamente, a propriedade é o domínio de uma disciplina em relação à popularidade de um conceito, em comparação a outras disciplinas que pesquisam o mesmo tema. $\mathrm{O}$ limiar em que um tema se torna "propriedade" de uma disciplina é arbitrário. Defendemos, no entanto, que ele pode ser observado uma vez que um determinado tema seja publicado em uma disciplina muito mais do que nas outras.

\section{Avaliação da relação}

Conceituamos a relação entre sociologia e ciência política como a medida em que (a) cada disciplina assume a "propriedade" sobre um tema específico, e, (b) ao publicar sobre o mesmo tema, elas citam uma à outra em seus periódicos mais influentes. Isso é mensurado através das citações em artigos completos ${ }^{13}$ publicados nos principais periódicos de cada disciplina. Esses são os principais meios de comunicação científica; tais periódicos associados a uma determinada disciplina refletirão as tendências da mesma. Analisamos tanto o número total de citações cruzadas quanto o de citações cruzadas entre artigos sobre o tema da democra-

\footnotetext{
${ }^{12} \mathrm{O}$ termo original "ownership" também pode ser traduzido como "propriedade intelectual". A melhor tradução para "ownership" no sentido apresentado pelo autor seria "domínio", mas optou-se por manter propriedade para maior coerência com o texto original (Nota da tradutora). ${ }^{13}$ Um artigo é definido como "um trabalho de pesquisa publicado", Segundo a página de ajuda da Web of Science.
} 
cia. As citações refletem em que periódico o tema foi publicado, mas não quem os publicou. Por exemplo, um artigo sobre democracia publicado na American Sociological Review contaria como estando dentro da sociologia, mesmo que seja de autoria de um cientista político por formação ou afiliação. Para obter a maior cobertura possível de produção acadêmica - e assim justificar a propensão das ciências sociais tanto para produzir como para citar livros e capítulos de livros mais do que outras ciências (Hicks, 1999) - coletamos citações do conjunto dos seguintes elementos: artigo, livro, capítulo de livro, resenha de livro, material editorial, carta, trabalho apresentado em congresso e resenha.

Os dados sobre citações de artigos foram extraídos da Web of Science, uma plataforma de pesquisa que fornece serviços de indexação e de busca e permite acessar e analisar informações sobre o conteúdo e os metadados de documentos de pesquisa de várias disciplinas. Utilizando informações sobre periódicos incluídos na Principal Coleção da Web of Science, foram coletados dois tipos de dados: (1) informação sobre a frequência de ocorrência de palavras-chave escolhidas em artigos de todas as revistas de sociologia e ciência política e (2) dados sobre citações cruzadas entre os principais periódicos de ambas as disciplinas.

Selecionamos periódicos de sociologia e ciência política que (a) estejam listados na Web of Science, (b) tenham um alto fator de impacto médio em 5 anos, e (c) figurem entre as principais publicações de interesse geral na disciplina ou tenham destaque entre revistas especializadas para artigos que cruzem ciência política e sociologia política. Em ordem alfabética (fator de impacto entre parênteses), para a sociologia eles são: American Journal of Sociology $(5,239)$, American Sociological Review $(5,563)$, Annual Review of Sociology $(6,672)$, British Journal of Sociology (2.194), European Sociological Review (2,226), Mobilization (1.069), Social Forces (2.412) e Sociological Theory (2.345). Para a ciência política 
Sociologias, Porto Alegre, ano 17, no 38, jan/abr 2015, p. 92-120

são: American Journal of Political Science $(3,96)$, American Political Science Review (4,516), Annual Review of Political Science (4,009), British Journal of Political Science $(2,284)$, Comparative Political Studies $(2,46)$, Journal of Democracy $(1,353)$, e Journal of Politics $(2,387)$.

Pode-se argumentar que a escolha dos periódicos introduz uma parcialidade na seleção no sentido de que as publicações de interesse geral são muito voltadas às disciplinas, e, portanto, não são interdisciplinares. Presumimos que o grau de multidisciplinaridade do foco de um periódico influencie na medida em que os artigos publicados nele citam artigos de publicações de outras disciplinas acadêmicas. Para explicar isso, incluimos duas publicações multidisciplinares, Politics \& Society $(2,301)$ e Social Science Quarterly $(1,407)$, que têm maior potencial para integração em termos de sociologia e ciência política.

O objetivo de nossa análise é mostrar a proporção da popularidade, da propriedade e das citações cruzadas entre periódicos de sociologia e ciência política. Apresentamos as informações com base nas grandes mudanças na popularidade e na "propriedade" das disciplinas entre 1945 e 2013, observando os pontos de ruptura em que uma disciplina assumiu a propriedade do tema, o que para a maioria dos temas, excetuando sociedade civil, se torna visível por volta de 1970. Isso faz sentido, já que esse foi o ano em que a ciência política e a sociologia iniciaram um longo período de ruptura e de autoquestionamento quanto às suas identidades disciplinares (Sigelman 2010, p. 884). Assim, para a análise de citações cruzadas, escolhemos a década de 1970 como o início. 


\section{Resultados}

Popularidade e propriedade dos principais conceitos em sociologia política

Primeiramente, traçamos tendências da popularidade relativa e da propriedade dos principais conceitos da sociologia política. A Figura 1 apresenta a história da democracia como tema em qualquer produção acadêmica entre 1945 e 2013. O estudo da democracia como tema não teve expressão até meados da década de 1970, passando de cerca de 200 produções por ano em 1975 para 400 produções por ano uma década depois. Na década que iniciou em 2010, desenvolveram-se mais de 3.600 produções por ano no tema da democracia. Em qualquer medida, esse é um crescimento meteórico em apenas 40 anos.

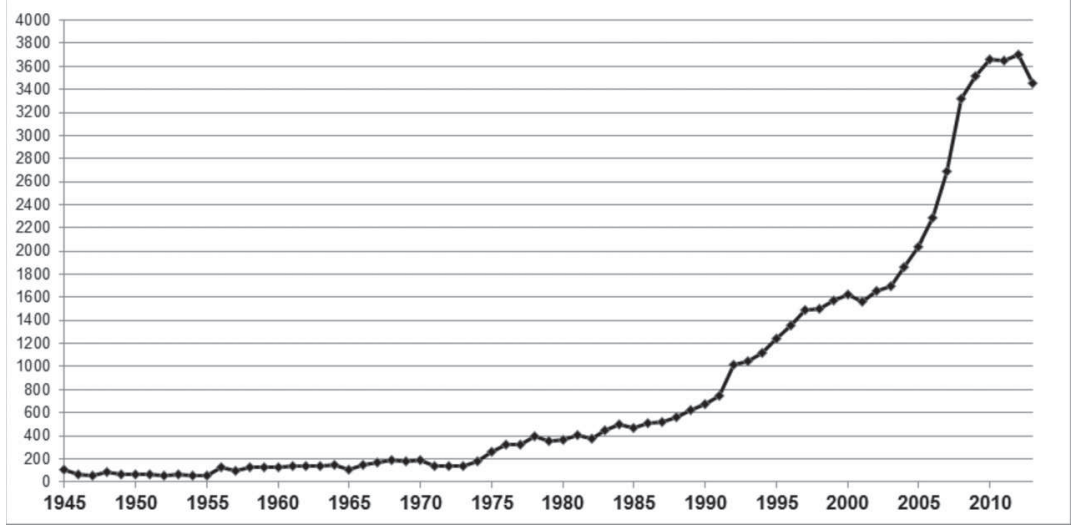

Figura 1. A democracia com tema em qualquer produção acadêmica em qualquer disciplina, 1945-2013. 
Sociologias, Porto Alegre, ano 17, no 38, jan/abr 2015, p. 92-120

Em seguida, nos voltamos às fontes disciplinares de pesquisa em sociologia política, de forma geral, a partir de 1970 até o presente. Desde 1970, mais de 55.000 trabalhos sobre o tema da democracia foram publicados. As fontes disciplinares de pesquisa sobre democracia são variadas e abrangem as ciências sociais e humanas, bem como a produção propositadamente interdisciplinar (estudos regionais sendo os mais proeminentes). No entanto, há uma evidente liderança na colaboração disciplinar: cerca de $40 \%$ de toda produção está em canais da ciência política. Isso é quase a soma das próximas cinco disciplinas combinadas (relações internacionais, história, sociologia, estudos regionais e economia). Se alguma disciplina detém a "propriedade" do estudo da democracia, é a ciência política. 
Sociologias, Porto Alegre, ano 17, no 38, jan/abr 2015, p. 92-120

Tabela 1. As vinte principais fontes de pesquisa que figuram em qualquer produção acadêmica sobre "Democracia", 1970-2013

\begin{tabular}{l|c}
\hline Disciplina & Frequência \\
\hline Ciência Política & 20,189 \\
\hline Relações Internacionais & 5,540 \\
\hline História & 5,502 \\
\hline Sociologia & 3,959 \\
\hline Estudos Regionais & 3,860 \\
\hline Economia & 3,612 \\
\hline Ciências Sociais Interdisciplinares & 2,561 \\
\hline Humanas Multidisciplinar & 2,096 \\
\hline Direito & 2,063 \\
\hline Administração Pública & 2,046 \\
\hline Planejamento e Desenvolvimento & 1,981 \\
\hline Filosofia & 1,868 \\
\hline Educação e Pesquisa em Educação & 1,718 \\
\hline Comunicação & 1,543 \\
\hline Questões Sociais & 1,403 \\
\hline Estudos ambientais & 911 \\
\hline Religião & 894 \\
\hline Ética & 766 \\
\hline Geografia & 718 \\
\hline Ciência da Informação e Biblioteconomia & 696 \\
\hline Produção total & 55,725 \\
\hline
\end{tabular}

Os conceitos-satélite da democracia - participação política, sociedade civil e movimentos sociais - são, em geral, menos populares, e tiveram que esperar por sua fase de crescimento rápido e trajetórias marcantes até a década de 1990, quando a pesquisa sobre a sociedade civil assumiu a liderança no que diz respeito ao número de publicações. Desde então, 
há uma separação clara na popularidade dos temas, com 'sociedade civil' claramente à frente, seguida dos tópicos 'movimentos sociais' e 'participação política' respectivamente em segundo e terceiro lugares. No final dos anos 2000 e no início dos anos 2010, produziram-se entre 800 e 900 trabalhos acadêmicos por ano sobre sociedade civil, em comparação a cerca de 450 para movimentos sociais e 250 para participação política.

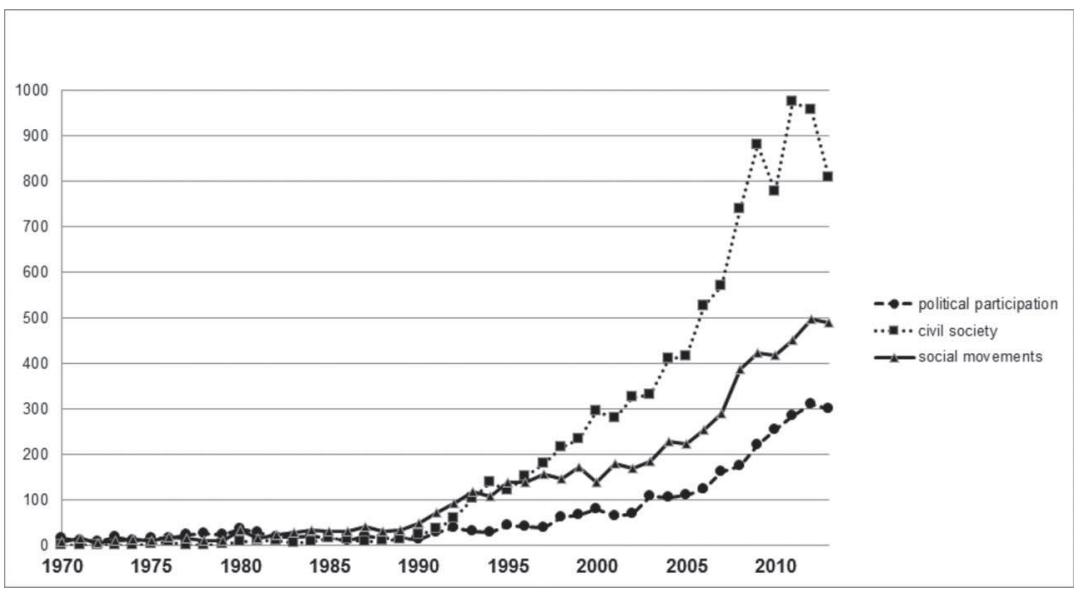

Figura 2. Participação política, sociedade civil e movimentos sociais como tema em qualquer produção acadêmica em qualquer disciplina, 1970-2013.

Considerando-se que a ciência política e a sociologia são as precursoras do estudo da sociologia política, examinamos as diferenças entre suas contribuições disciplinares relativas para os principais conceitos. A Figura 3 apresenta as diferenças entre essas duas disciplinas no estudo da democracia. A separação entre as duas ocorreu em meados dos anos 1970, exatamente quando a democracia em si experimentava uma "onda" e passou a pertencer à ciência política. A separação entre a sociologia e a ciência política em termos de participação política e sociedade 
Sociologias, Porto Alegre, ano 17, no 38, jan/abr 2015, p. 92-120

civil ocorreu muito mais tarde, na década de 1990 (Figuras 4 e 5). Até então, a sociologia disputava com a ciência política ser a referência para publicação d pesquisas nessa área da sociologia política.

Igualmente importante é o fato de que, entre 1945 e 1970 - um total de 25 anos, durante os quais as ciências sociais tinham atingido seu auge - a sociologia e a ciência política tinham quase a mesma tendência de publicar obras sobre os principais conceitos da sociologia política, incluindo a democracia. A separação veio depois de 1970 e se acelerou nas décadas de 1990 e 2000, justamente quando a ideia de interdisciplinaridade começou a se tornar um jargão bem financiado em universidades americanas. Portanto, a sociologia política rapidamente reduziu seu potencial interdisciplinar no exato momento em que a interdisciplinaridade se tornou popular.

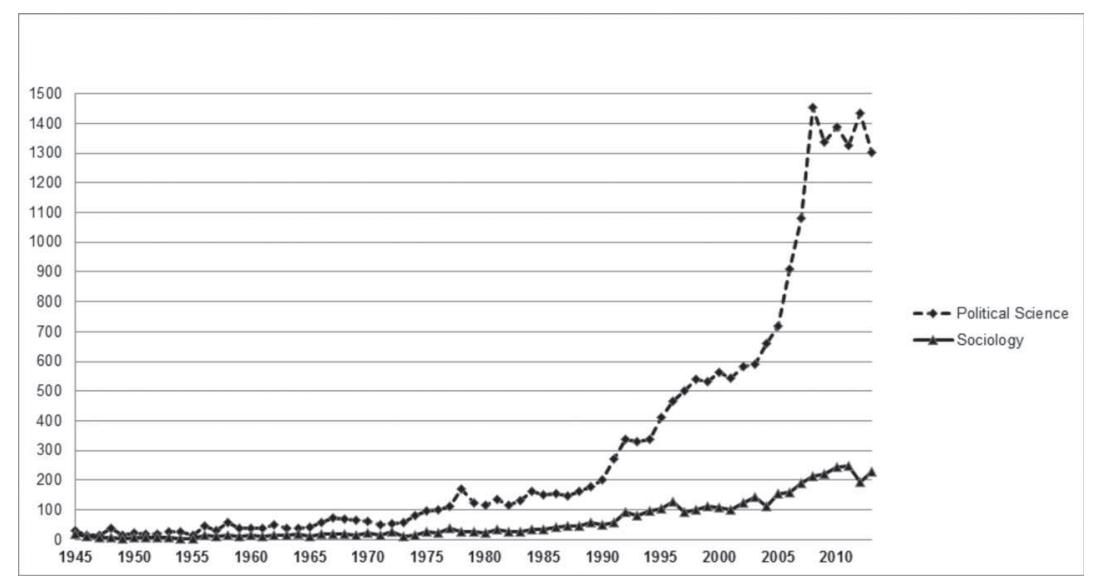

Figura 3. A democracia acadêmica como tema em qualquer produção acadêmica para a ciência política e a sociologia, 1945-2013. 


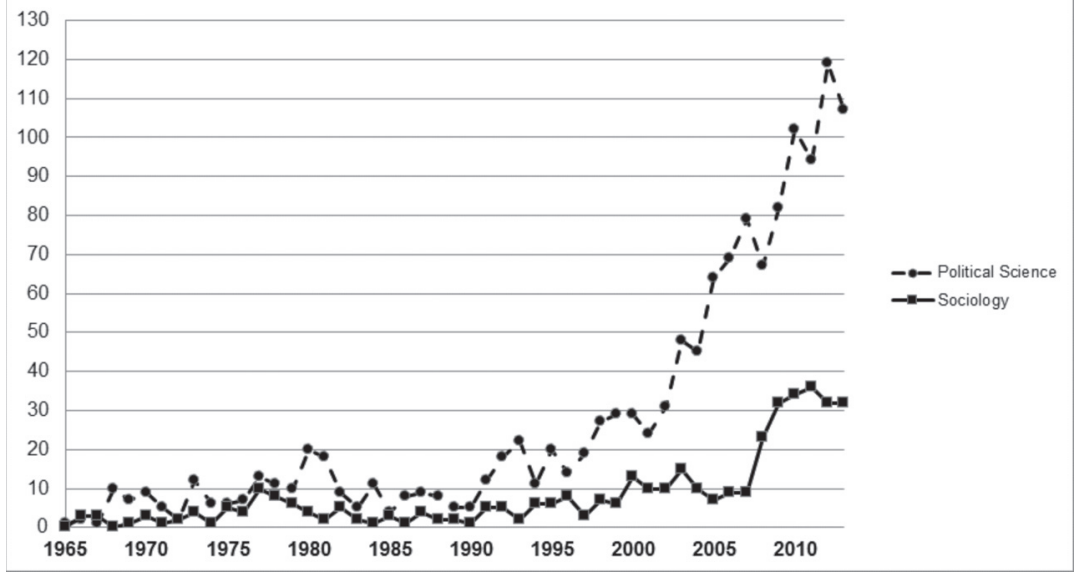

Figura 4. A participação política como tema em qualquer produção acadêmica para a ciência política e a sociologia, 1965-2013.

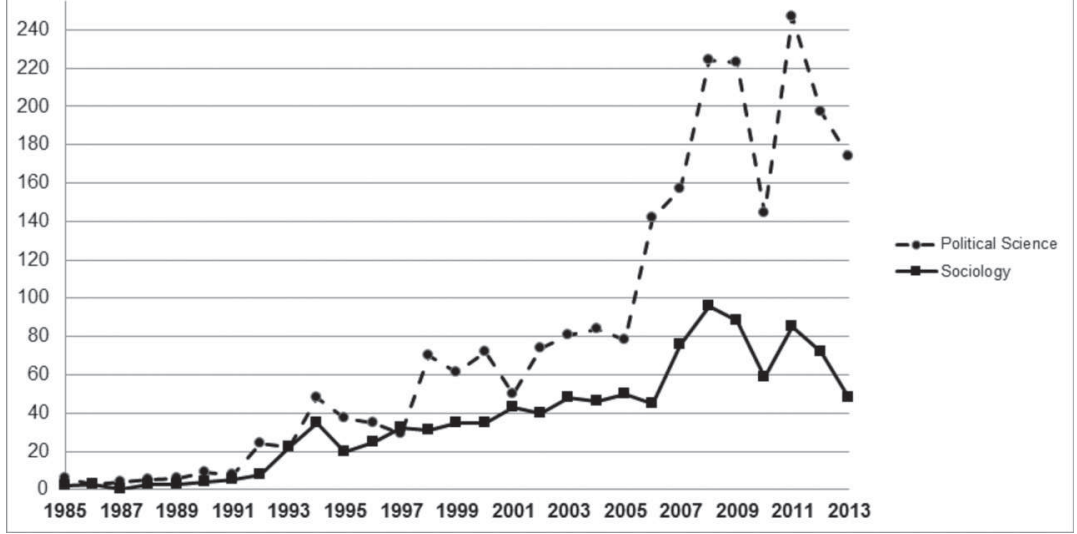

Figura 5. A sociedade civil como tema em qualquer produção acadêmica para a ciência política e sociologia, 1985-2013. 
Sociologias, Porto Alegre, ano 17, no 38, jan/abr 2015, p. 92-120

Os movimentos sociais são a exceção. Enquanto a década de 1960 viu uma relativa paridade entre as disciplinas, esse conceito central na sociologia política tornou-se lentamente uma atribuição da sociologia, mais do que da ciência política. Por volta dos anos de 2010, a sociologia havia se tornado um destino para publicações de pesquisa sobre movimentos sociais. A diferença não é muito grande, e não se pode dizer que o estudo dos movimentos sociais pertence à sociologia. No entanto, uma diferença notável surgiu, num contexto em que a ciência política é o destino mais provável para pesquisas sobre a maior parte dos temas centrais da sociologia política.

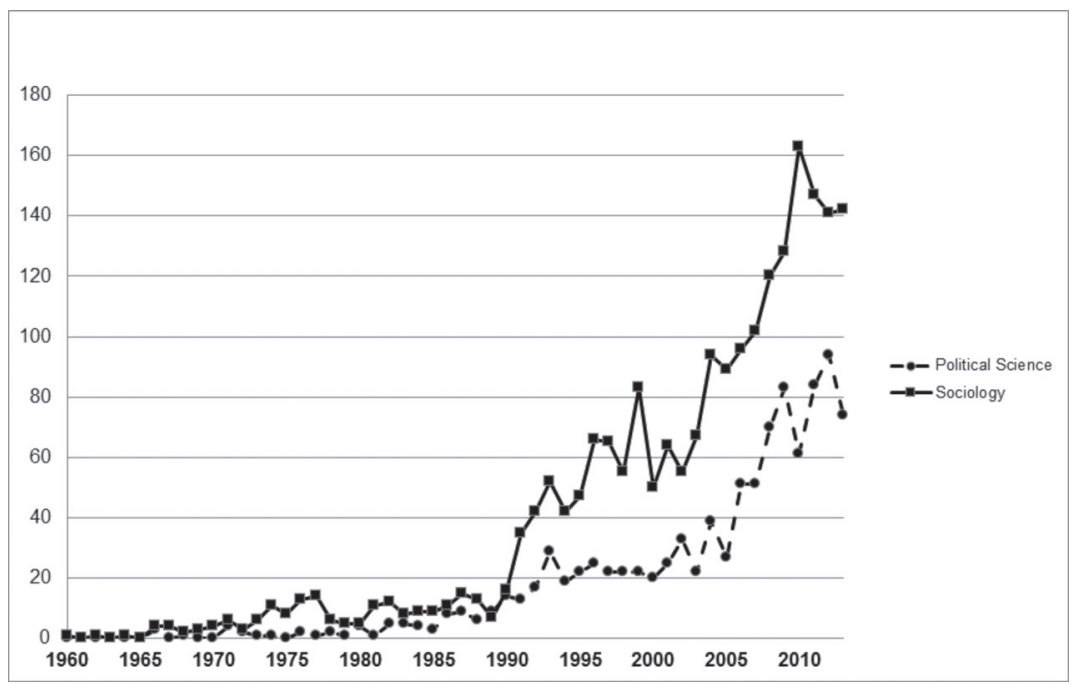

Figura 6. Os movimentos sociais como tema em qualquer produção acadêmica para a ciência política e a sociologia, 1960-2013. 
Sociologias, Porto Alegre, ano 17, no 38, jan/abr 2015, p. 92-120

Em suma, a ciência política domina o estudo da democracia, não apenas em comparação com a sociologia, mas também em relação a todas as outras disciplinas. As substanciais lacunas entre a ciência política e a sociologia no que tange aos conceitos-satélite da democracia indicam que a sociologia política está mais situada na ciência política do que na sociologia. No entanto, as lacunas não são desmedidas, o que indica haver ainda potencial para uma relação interdisciplinar. Pode-se avaliar se essa relação é forte e simétrica através de citações cruzadas nos principais periódicos de cada área.

\section{Relações disciplinares entre a sociologia e a ciência política}

Apresentamos dados de citações cruzadas de mais de 40 anos (entre 1970 e 2013) para os principais periódicos da sociologia e da ciência política para todos os principais conceitos - democracia, participação política, sociedade civil e movimentos sociais - e para democracia isoladamente. A Tabela 2 apresenta o número bruto de citações de artigos para as principais publicações de sociologia listadas anteriormente, e a Tabela 3 apresenta o mesmo, mas para os principais periódicos de ciência política. Por exemplo, na Tabela 2, o American Journal of Sociology citou artigos das principais revistas de ciência política 210 vezes, e é citado por essas mesmas revistas 608 vezes.

Cada tabela possui duas colunas que contêm a razão entre receber (o principal periódico de uma disciplina é citado pelos principais periódicos da outra disciplina) e dar (o principal periódico de uma disciplina cita os principais periódicos da outra disciplina). Razões equivalentes a 1 significam que a relação é simétrica: a revista dá e recebe em igual medida. Índices acima ou abaixo da pontuação 1 significam que a relação é assimétrica. Se for superior a 1, o periódico dá mais do que recebe. Se 
for inferior a 1, ele recebe mais do que dá. Ao classificar relações disciplinares, consideramos as de pontuação 1, ou muito próxima de 1, como sendo fortes e simétricas. As pontuações 2 ou superior, e 0,50 ou inferior, são consideradas fracas e assimétricas. Usando o exemplo da Tabela 2, o American Journal of Sociology, no estudo da democracia, dá mais para a ciência política do que recebe, com um índice de 3,5.

Tabela 2. Número de citações de artigos: como os periódicos de ciência política citam e são citados pelos principais periódicos de sociologia, 1970-2013 ${ }^{14}$

\begin{tabular}{l|c|c|c|c|c|c}
\hline & \multicolumn{3}{|c|}{ Todos os temas } & \multicolumn{3}{c}{ "Democracia" } \\
\hline $\begin{array}{l}\text { Periódico de sociologia (data de } \\
\text { fundação entre parênteses) }\end{array}$ & $\begin{array}{c}\text { Cita os } \\
\text { principais } \\
\text { periódicos } \\
\text { de ciência } \\
\text { política }\end{array}$ & $\begin{array}{c}\text { É citado } \\
\text { por um } \\
\text { dos } \\
\text { principais } \\
\text { periódicos } \\
\text { de ciência } \\
\text { política }\end{array}$ & $\begin{array}{c}\text { Proporção } \\
\text { de “ } \\
\text { Écitado" } \\
\text { para "Cita" } \\
\text { por um } \\
\text { dos } \\
\text { principais } \\
\text { periódicos } \\
\text { de ciência } \\
\text { política } \\
\text { perincipais } \\
\text { de ciência } \\
\text { política }\end{array}$ & $\begin{array}{c}\text { Razão } \\
\text { entre } \\
\text { "É citado" } \\
\text { e "Cita" }\end{array}$ \\
\hline $\begin{array}{l}\text { American Journal of Sociology } \\
\text { (1895, 1899) }\end{array}$ & 210 & 608 & 2,90 & 10 & 35 & 3,50 \\
\hline American Sociological Review (1936) & 299 & 818 & 2,74 & 32 & 98 & 3,06 \\
\hline Annual Review of Sociology (1975) & 68 & 86 & 1,26 & 3 & 5 & 1,67 \\
\hline British Journal of Sociology (1950) & 76 & 78 & 1,03 & 7 & 1 & 0,14 \\
\hline European Sociological Review (1985) & 120 & 49 & 0,41 & 13 & 7 & 0,54 \\
\hline Mobilization (1996) & 84 & 10 & 0,12 & 7 & 0 & 0,00 \\
\hline Social Forces (1922) & 284 & 231 & 0,81 & 24 & 12 & 0,50 \\
\hline Sociological Theory (1994) & 30 & 15 & 0,50 & 3 & 0 & 0,00 \\
\hline Politics \&Society (1970) & 141 & 308 & 2,18 & 23 & 37 & 1,61 \\
\hline Social Science Quarterly (1969) & 514 & 527 & 1,03 & 15 & 8 & 0,53 \\
\hline
\end{tabular}

${ }^{14}$ As datas de fundação não correspondem necessariamente ao registro mais antigo na base de dados da WoS. Seguem as exceções: Politics \& Society: primeiro registro na WoS em 1970, depois em 1974 e anualmente a partir de então. Social Science Quarterly: primeiro registro em 1969, depois em 1971, e então anualmente. 
Sociologias, Porto Alegre, ano 17, no 38, jan/abr 2015, p. 92-120

Tabela 3. Número de citações de artigos: como os periódicos de sociologia citam e são citados pelos principais periódicos de ciência política, 1970-2013 $3^{15}$

\begin{tabular}{l|c|c|c|c|c|c}
\hline & \multicolumn{3}{|c|}{ Todos os temas } & \multicolumn{3}{c}{ "Democracia" } \\
\hline $\begin{array}{l}\text { Periódico de ciência política (data } \\
\text { de fundação entre parênteses) }\end{array}$ & $\begin{array}{c}\text { Cita os } \\
\text { principais } \\
\text { periódicos } \\
\text { de } \\
\text { Sociologia }\end{array}$ & $\begin{array}{c}\text { É citado } \\
\text { por um } \\
\text { dos } \\
\text { principais } \\
\text { periódicos } \\
\text { de } \\
\text { Sociologia }\end{array}$ & $\begin{array}{c}\text { Proporção } \\
\text { de } \\
\text { "É citado" } \\
\text { para "Cita" }\end{array}$ & $\begin{array}{c}\text { Cita os } \\
\text { principais } \\
\text { periódicos } \\
\text { de um } \\
\text { dos } \\
\text { Sociologia } \\
\text { principais } \\
\text { periódicos } \\
\text { de } \\
\text { Sociologia }\end{array}$ & $\begin{array}{c}\text { Razão } \\
\text { entre } \\
\text { e "Citado" }\end{array}$ \\
\hline $\begin{array}{l}\text { American Journal of Political Science } \\
\text { (1956) }\end{array}$ & 316 & 428 & 1,35 & 19 & 30 & 1,58 \\
\hline $\begin{array}{l}\text { American Political Science Review } \\
\text { (1906) }\end{array}$ & 296 & 697 & 2,35 & 13 & 54 & 4,15 \\
\hline $\begin{array}{l}\text { Annual Review of Political Science } \\
\text { (1998) }\end{array}$ & 66 & 74 & 1,12 & 8 & 9 & 1,13 \\
\hline $\begin{array}{l}\text { British Journal of Political Science } \\
\text { (1971) }\end{array}$ & 144 & 214 & 1,49 & 17 & 19 & 1,12 \\
\hline Comparative Political Studies(1968) & 265 & 202 & 0,76 & 58 & 29 & 0,50 \\
\hline Journal of Democracy (1990) & 15 & 28 & 1,87 & 3 & 5 & 1,67 \\
\hline Journal of Politics (1939) & 276 & 257 & 0,93 & 22 & 23 & 1,05 \\
\hline Politics \& Society (1970) & 134 & 310 & 2,31 & 6 & 12 & 2,00 \\
\hline Social Science Quarterly (1969) & 518 & 709 & 1,37 & 7 & 2 & 0,29 \\
\hline
\end{tabular}

\footnotetext{
${ }^{15}$ As datas de fundação não correspondem necessariamente ao registro mais antigo na base de dados da WoS. Seguem as exceções: American Journal of Political Science: primeiro registro em 1973. Journal of Democracy: primeiro registro em 1995. Social Science Quarterly: primeiro registro em 1969, depois em 1971, e então anualmente.
} 
Para todos os temas combinados, e para o estudo da democracia em particular, a relação disciplinar entre a sociologia e a ciência política é fraca e assimétrica: apenas sete dos dezesseis principais periódicos têm uma relação relativamente forte e simétrica com a outra disciplina. Quando se limita o tema ao da democracia, esse número cai para cinco em dezesseis. As relações com os principais canais da sociologia entre periódicos emblemáticos da ciência política no estudo da democracia variam muito, uma vez que o AJPS dá 1,6 vezes mais à sociologia do que recebe e o APSR dá acima de quatro vezes mais. As publicações emblemáticas da sociologia -ASR e AJS - citam, em média, três vezes mais a ciência política do que são citados. Isso sugere uma relação disciplinar fraca e assimétrica entre periódicos emblemáticos. E há os extremos dos extremos: desde sua fundação, nos anos 1990, as revistas Sociological Theory e Mobilization nunca foram citadas por algum dos principais periódicos da ciência política no tema da democracia. A European Sociological Review raramente é citada por esses periódicos, embora os cite bastante.

Os periódicos híbridos, Politics \& Society e Social Science Quarterly, não são grandes fontes de publicações interdisciplinares. Essas revistas diferem na força e na simetria de suas relações com cada uma das duas disciplinas. A Politics \& Society tanto cita quanto recebe citações mais da ciência política do que da sociologia. A Social Science Quarterly tem uma relação mais simétrica para todos os temas combinados, mas difere no estudo da democracia. Neste, a revista cita menos a ciência política do que recebe citações, e parece apoiar-se mais nos principais periódicos de sociologia.

Outra forma de examinar a relação disciplinar entre sociologia e ciência política é através do percentual de citações de cada uma na outra disciplina. No tema da democracia, cerca de $40 \%$ das citações da sociologia vêm da ciência política; contudo, cerca de $6 \%$ das citações da ciência política vêm da sociologia. A ciência política é muito menos interdisciplinar no estudo da democracia, uma vez que tem mais que o dobro de probabilidade de citar a si mesma (58\%) do que a sociologia tem de fazer o mesmo (25\%). 
Sociologias, Porto Alegre, ano 17, no 38, jan/abr 2015, p. 92-120

Tabela 4. Citações cruzadas entre sociologia e ciência política com relação ao estudo da democracia

\begin{tabular}{l|c|c}
\hline & Sociologia & Ciência Política \\
\hline $\begin{array}{l}\text { Número total de artigos com o tema } \\
\text { democracia in 1970-2013 }\end{array}$ & 1924 & 9666 \\
\hline $\begin{array}{l}\text { Número de vezes em que esses artigos } \\
\text { foram citados por outros artigos }\end{array}$ & 10750 & 34772 \\
\hline $\begin{array}{l}\text { Número de vezes em que esses artigos } \\
\text { foram citados por outros artigos sobre } \\
\text { democracia }\end{array}$ & 2651 & 10649 \\
\hline $\begin{array}{l}\text { Número de vezes em que esses artigos } \\
\text { foram citados por artigos sobre demo- } \\
\text { cracia na mesma disciplina }\end{array}$ & 643 & 6148 \\
\hline $\begin{array}{l}\text { Número de vezes em que esses artigos } \\
\text { foram citados por artigos sobre demo- } \\
\text { cracia em outra disciplina }\end{array}$ & 1047 & 715 \\
\hline$\%$ de citações da própria disciplina & & \\
\hline$\%$ de citações de outra disciplina & $39.49 \%$ & $6.71 \%$ \\
\hline
\end{tabular}

\section{Conclusão e discussão}

Em suma, a relação entre a sociologia e a ciência política é fraca e assimétrica exatamente nas áreas centrais da sociologia política: democracia, participação política, sociedade civil e movimentos sociais. As contribuições disciplinares à sociologia política são enviesadas, uma vez que a maior parte de seus conceitos centrais são mais frequentes na ciência política. A exceção é o tema dos movimentos sociais, o qual, na sociologia política, parece ser o único que a sociologia chega a dominar. O fato de o estudo da democracia ser de domínio da ciência política, e de essa tender a citar a si mesma mais do que a sociologia, é indicativo de promessa frustrada da sociologia política como uma iniciativa interdisciplinar.

Desde 1945, quando as ciências sociais experimentavam sua ascendência (até os anos 1970) e grande potencial para interdisciplinaridade, a sociologia política via-se frente a dois caminhos: a fissura disciplinar entre 
a sociologia e a ciência política com relação aos seus principais conceitos ou tornar-se uma ponte interdisciplinar. Ao invés da interdisciplinaridade, tem-se uma crescente especialização e criação de limites disciplinares levando a que a sociologia e a ciência política raramente dialoguem (ver também Sigelman, 2010). Ao invés de ser uma ponte entre disciplinas, a sociologia política tornou-se duas pontes, ambas construídas dentro das duas ilhas acadêmicas constituídas pela sociologia e pela ciência política, e não uma que se estenda através do oceano que as separa.

O que em parte explica a separação entre sociologia e ciência política nos temas da sociologia política é a tendência geral à especialização na ciência. A especialização - consequência de vários fatores na organização do ensino superior e do meio acadêmico e da proliferação de canais de disseminação da pesquisa - é uma força inevitável quando a ciência é o meio e a complexidade é a norma (Sartori, 1969, p. 197). Jacobs (2014, p. 4) argumenta que a especialização é uma consequência natural do gerenciamento da crescente produção de conhecimento científico: [clom mais de 28.000 periódicos avaliados por pares sendo publicados atualmente e centenas de associações acadêmicas realizando congressos regularmente, não há arranjo organizacional para o meio acadêmico que possa evitar alguma forma de especialização. Van Deth (2010, p. 105) defende que os principais conceitos da sociologia política tornaram-se seus próprios subcampos, deixando a disciplina sem muito foco ou direção.

Para a sociologia política, a especialização e domínio dos temas aceleraram-se nos anos 1970, exatamente quando a ciência política ocidental enfrentava sua crise de identidade. Com o tempo, a ciência política tornou-se a referência para a produção de estudos sobre democracia, participação política e sociedade civil. Embora a sociologia política tenha sido um potencial destino para a colaboração interdisciplinar, muito mais cientistas políticos quiseram abordar seus principais conceitos - democracia, socieda- 
de civil e participação política - do que sociólogos, cujos objetos de estudo, com exceção dos sociólogos políticos, não precisam incluir a política.

Além da especialização, motivos externos também propiciaram essa fissura disciplinar. O mundo pós-segunda guerra produziu instruções relativamente claras para as pesquisas econômicas, sociais e políticas e criou uma grande demanda por conhecimento científico nos campos da governança democrática, economia de mercado e desigualdade social. O colapso do sistema bipolar, com a democracia de um lado e o autoritarismo do outro, o surgimento da China não democrática e economicamente bem-sucedida, o titubeante projeto de democratização no Oriente Médio e a crescente desigualdade no mundo ocidental suscitam questões sobre o aspecto "universal" dos valores democráticos. Uma única disciplina não dará conta de lidar com essas questões, o que só será possível por meio da efetiva colaboração entre diferentes campos disciplinares. Para que a interdisciplinaridade se torne uma realidade, ela deve ser um esforço consciente e focado na união dos conhecimentos disciplinares (Wagner et. al., 2011, p. 16-18). Superar as atuais brechas exigirá certo esforço por parte da organização dos programas de pós-graduação e também uma mudança nas escolhas dos conselhos editoriais dos principais periódicos das disciplinas.

Joshua Kjerulf Dubrow - Professor Associado do Instituto de Filosofia e Sociologia da Academia Polonesa de Ciências. $\$ dubrow.2@osu.edu.

Marta Kołczyńska - Pesquisadora assistente do Instituto de Filosofia e Sociologia da Academia Polonesa de Ciências. Estudante de Pós-Graduação do Departamento de Sociologia da Universidade do Estado de Ohio (2013-). \ mkolczynska@ifispan.waw.pl 
Sociologias, Porto Alegre, ano 17, no 38, jan/abr 2015, p. 92-120

\section{Referências}

1. ABBOTT, Andrew. Chaos of Disciplines. Chicago: University of Chicago Press, 2001.

2. ABBOTT, Andrew. The Order of Professionalization. Work and Occupations 18(4), 1991, p. 355-384.

3. CALHOUN, Craig (ed.). Sociology in America: A History. Chicago: University of Chicago Press.2007.

4. DETH, Jan van. Political Sociology: old concerns and new directions. In: MITRA,Subrata K.; PEHL, Malte; SPEISS, Clemens. Political Sociology: the state of the art. Opladen, Alemanha: Barbara Budrich Publishers, 2010, p.105-126.

5. DRYZEK, John S. Revolutions without Enemies: Key Transformations in Political Science. American Political Science Review 100 (4), 2006, p. 487-492.

6. DUBROW, Joshua Kjerulf. Sociology and American Studies: A Case Study in the Limits of Interdisciplinarity. The American Sociologist 42(4), 2011, p. 303-315.

7. DUBROW, Joshua Kjerulf; CORTES, Soraya Vargas. Guest Editors' Introduction: Democracy, Global Governance and Political Inequality. International Journal of Sociology 43(2), 2013, p. 3-12.

8. DUBROW, Joshua Kjerulf. Introduction: Political Inequality in an Age of Democracy. In:DUBROW, Joshua Kjerulf (Ed.). Political Inequality in an Age of Democracy: Cross-national Perspectives. Londres: Routledge. 2014.

9. FARR, James. Political Science. In: PORTER,Theodore M; ROSS, Dorothy (Eds.). The Cambridge History of Science: The Modern Social Sciences, v. 7. Cambridge: Cambridge University Press, 2003.

10. GOVE, Walter R. The Review Process and Its Consequences in the Major Sociology Journals. Contemporary Sociology 8(6), 1979, p. 799-804.

11. GUNNELL, John G. The Founding of the American Political Science Association: Discipline, Profession, Political Theory and Politics. American Political Science Review 100(4), 2006, p. 479-486.

12. HICKS, Alexander. Is Political Sociology Informed by Political Science? Social Forces 73(4), 1995, p. 1219-1229.

13. HICKS, Diana. The Difficulty of Achieving Full Coverage of International Social Science Literature and the Bibliometric Consequences. Scientometrics 44(2), 1999, p. 193-215.

14. JACOBS, Jerry A. In Defense of Disciplines: Interdisciplinarity and Specialization in the Research University. Chicago: University of Chicago Press.2014. 
15. JACOBS, Jerry A; FRICKEL; Scott. Interdisciplinarity: A Critical Assessment. Annual Review of Sociology 35, 2009, p. 43-65.

16. JANOSKI, Thomas; ALFORD, Robert R.; HICKS, Alexander M.; SCHWARTZ, Mildred A. (Eds.). The Handbook of Political Sociology: States, Civil Societies, and Globalization. Cambridge University Press, 2005.

17. LIPSET S. M., BENDIX R. Political Sociology - A Trend Report and Bibliography. Current Sociology, 6, 1957, p. 79-169.

18. MITRA, Subrata K.; PEHL, Malte. Introduction. In: MITRA,Subrata K.; PEHL,Malte; SPEISS,Clemens. Political Sociology: The State of the Art. (World of Political Science - The State of the Discipline). Opladen, Alemanha: Barbara Budrich Publishers, 2010. P. 13-30.

19. NATIONAL ACADEMIES. Facilitating Interdisciplinary Research. Washington D.C.: National Academies Press, 2004.

20. PORTER, Theodore M. Statistics and Statistical Methods. In: PORTER, Theodore M.;ROSS, Dorothy (Eds.). The Cambridge History of Science: The Modern Social Sciences, v. 7. Cambridge: Cambridge University Press. 2003.

21. ROSS, Dorothy. Changing Contours of the Social Science Disciplines. In: PORTER, Theodore M.; ROSS, Dorothy (Eds.). The Cambridge History of Science: The Modern Social Sciences, v. 7. Cambridge: Cambridge University Press. 2003.

22. SARTORI, G.. From the Sociology of Politics to Political Sociology. In: LIPSET, S.M. (ed.) Politics and the Social Sciences. New York: Oxford University Press, 1969.

23. SIGELMAN, Lee. Terminological interchange between Sociology and Political Science. Social Science Quarterly 91(4), 2010, p. 883-905.

24. STEIN, Michael; TRENT, John. Foreword. In: MITRA, Subrata K.; PEHL, Malte; SPEISS, Clemens. Political Sociology: The State of the Art. Opladen, Alemanha: Barbara Budrich Publishers, 2010. P. 7-8.

25. WAGNER, Caroline S. et al. Approaches to understanding and measuring interdisciplinary scienti $\square$ c research (IDR): A review of the literature. Journal of Infometrics. 165, 2011, p.14-26.

26. WALDER, Andrew G. Political Sociology and Social Movements. Annual Review of Sociology 35, 2009, p. 393-412.

27. YOUNG, Cristobal. The emergence of sociology from political economy in the United States: 1890 to 1940. Journal of the History of the Behavioral Sciences. Vol. 45 (2), 2009, p. 91-116.

Recebido em: 24/06/2014

Aceite final: 12/08/2014 